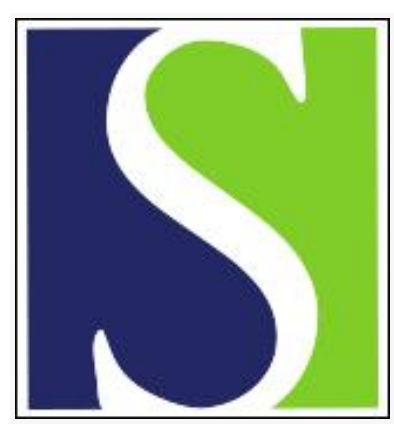

Scand J Work Environ Health 1997;23(6):401-402

https://doi.org/10.5271/sjweh.261

Issue date: Dec 1997

\title{
A smoke screen to keep the controversy alive
}

by Kobayashi F, Vainio H, Sasco AJ

This article in PubMed: www.ncbi.nlm.nih.gov/pubmed/9476802

\section{(c) (i)}


Scand J Work Environ Health 1997;23:401-2

\section{A smoke screen to keep the controversy alive}

In the early days of awareness about cigarette smoking, scientists, clinicians, and public health officers focused their attention on the effects of smoking on smokers, with the general conclusion that smoking cigarettes, cigars, or pipes can cause a wide range of illnesses, from lung cancer to heart disease. Nevertheless, tobacco industry representatives have continued to deny the causality between, for example, smoking cigarettes and lung cancer. Very recently, however, Philip Morris's chief executive officer broke the tradition, admitting that cigarette-related deaths were possible. This event occurred on 21 August 1997 during his testimony in relation to the state of Florida's USD 12.3 billion lawsuit against cigarette makers. This acknowledgment is a dramatic turnaround for tobacco industries, which have thus far questioned the link between tobacco and cancer. The chief executive, however, played it down by adding that he would like to see proof from his own scientists that cigarettes actually cause lung cancer.

About one-quarter of Scandinavians are "active" smokers, but almost everyone is at some point a "passive" smoker. In the United States, the Center for Disease Control has reported that nearly 9 out of 10 nonsmokers have had detectable amounts of cotinine, a metabolic residue from inhaled nicotine, in their blood. Therefore, the focus has shifted to how the active smoker's fumes affect nonsmokers' health. Environmental tobacco smoke is a mixture of sidestream and exhaled mainstream smoke. Although it contains the same toxic and carcinogenic constituents as the mainstream smoke inhaled by smokers, sidestream smoke contains more unburnt hydrocarbons and is a more potent mutagen on a weight basis. Vulnerable groups in society - infants, children, adults with asthma and respiratory conditions, and persons with established cardiac diseases - are the most affected by exposure to environmental tobacco smoke (1). The strategy of the tobacco industry, however, has been to "coordinate and pay scientists on an international basis to keep the environmental tobacco smoke controversy alive", as seen in a leaked memorandum (dated February 1988), which plainly set out the Philip Morris Company's worldwide strategy (2): "the consultants should, ideally, be scientists who have no previous association with tobacco companies and who have no previous record on the primary issues". It also suggested that, once a scientist crosses over to the tobacco industry, checks keep coming in. The strategy has been applied in various parts of the world including, obviously, Europe. Court cases in Finland revealed that the industry "headhunters" had found an ideal "consultant" for their purposes, a professor of anatomy with an excellent record in basic research but with no experience in research relating to tobacco and cancer. This person was the industry's "main" special witness in the cases against the tobacco industry in Finland.

The significance of the work of such "consultants" was illustrated last year when Philip Morris ran full-page advertisements in European newspapers purporting to provide scientific evidence that the risks of passive smoking were equal to those of innocent activities such as drinking 2 glasses of whole milk per day or eating biscuits. The campaign was attacked by many scientists as being misleading $(3,4)$. The central message of the advertisement was that passive smoking is not "really a meaningful health risk to people who have chosen not to smoke". Readers were told to write for a copy of a report called "Environmental Tobacco Smoke and Lung Cancer: an Evaluation of the Risk" by a team referred to as the European Working Group on Environmental Tobacco Smoke and Lung Cancer. The working group turned out to be an industry-funded enterprise, consisting of "consultants" with "no previous record on the primary issues".

The main tactic of the tobacco industry is to promote the impression that there is considerable scientific controversy and uncertainty about the effects of smoking on health. One of their arguments is the lack of evidence from animal models; however, since publication of the paper by Witschi et al (5), that argument has been invalidated. The associations between passive smoking and disease are undeniably beset with methodological problems, but, those notwithstanding, the Cancer Experts Committee of 
the European Union recommended that, in order "to protect the rights of non-smokers and prevent involuntary exposure to environmental tobacco smoke, smoking be banned in public places and in the workplace" and that separate smoking sections be introduced in "places such as restaurants and bars". Similar recommendations have been made in other parts of the world, for example, Australia (1). They are not based on isolated studies with potential methodological flaws, but on the total weight of evidence derived from 10 s of studies carried out by different independent scientists, in various population groups, which show, for the vast majority, increased risks of diseases for passive smokers. For active smokers, hundreds of epidemiologic studies have produced concordant results, backed up by both experimental and genetic studies (6), strongly indicating the causal nature of the association between exposure to tobacco smoke and cancer (7).

For many people, work is a major source of exposure to other people's tobacco smoke. Some occupational groups, such as bar and restaurant workers, experience particularly high levels of such smoke (8). In the United States, the Occupational Safety and Health Administration has classified environmental tobacco smoke as a potential occupational carcinogen. Many countries, such as the Nordic countries, have introduced strict limitations on smoking at workplaces, banned smoking in public places, and require nonsmoking sections in restaurants.

The tobacco industry's strategies are cleverly tailored to undermine the activities of public health authorities. The working group supported by the tobacco industry suggested that the level of carcinogens in environmental tobacco smoke is too low to be of concern, and, furthermore, it referred to the hormesis-phenomenon: the suggestion that low-level exposures are beneficial because they stimulate bodily defenses and thus reduce the risk of cancer. No evidence to support the implication that a small dose of environmental tobacco smoke is beneficial was given by the working group - it was just an obvious attempt to dismiss concerns about low levels of exposure.

The tactic of the tobacco industry is to influence public opinion against the action of health authorities through selective funding of research, support of the publication of proindustry opinions, and intimidate its opponents. Some scientists are used by the tobacco industry as "consultants" to participate in the production of documents that threaten public health and "to keep the controversy alive". In spite of the efforts of the tobacco industry's "consultants" to cast doubt on the health damaging effects of environmental tobacco smoke, the weight and consistency of the epidemiologic and experimental evidence is strongly in favor of the causal link between exposure to environmental tobacco smoke and various diseases, such as lung cancer and cardiovascular diseases. In light of this evidence, occupational health officers should take every action to stop people from smoking at work and to diminish exposure to environmental tobacco smoke. They should not be mislead by the "smoke screen" from tobacco industry "consultants".

\section{References}

1. Woodward A, Jamrozik K. Passive smoking: what are the limits to liberty? Med J Aust 1996;164:260—1.

2. Chapman S. Tobacco industry memo reveals passive smoking strategy. BMJ 1997;314:1569.

3. Boffetta P, Vainio H, Saracci R. Epidemiology versus a smoke screen [letter]. Lancet 1996;348:410.

4. Smith GD, Phillips AN. Passive smoking and health: should we believe Philip Morris's "experts"? BMJ 1996;313:92933.

5. Witschi H, Espiritu I, Peake JL, Wu K, Maronpot RR, Pinkerton KE. The carcinogenicity of environmental tobacco smoke. Carcinogenesis 1997;18:575-86.

6. Denissenko MF, Pao A, Tang M, Pfeifer GP. Preferential formation of benzo[a]pyrene adducts at lung cancer mutational hotspots in p53. Science 1996;274:430-2.

7. International Agency for Research on Cancer (IARC). Tobacco smoking. Lyon: IARC, 1986. IARC monographs on the evaluation of carcinogenic risks to humans, vol 38.

8. Woodward A. Is passive smoking in the workplace hazardous to health? Scand J Work Environ Health 1991;17:293 301.

Harri Vainio, MD, ${ }^{\dagger}$ Annie J Sasco, $M D^{\prime}$

1 International Agency for Research on Cancer

150 cours Albert Thomas

F-69372 Lyon Cedex 08

France 